\title{
Grief on the phone
}

Cite as: CMAJ 2020 December 7;192:E1732. doi: 10.1503/cmaj.201916

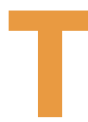
he patient on the other end of the telephone line goes silent. I hold my breath to see if she can catch hers. A muffled sob tells me she is crying. In palliative care we are taught that interrupting these moments by rushing for tissues or words conveys that we are not okay with our patient's tears of grief. I am comfortable with stillness when tears come.

In the cancer centre, despite shocking fluorescent lights and awkward wheeled seats, weighed down by my white coat and the moment, I had mastered the art of "holding space." With hunched bodies and lined eyes, patients told me what they needed without speaking. Their bodies asked for patience. Their bodies asked for time. Even when my own body ached from the sadness pooled in their eyes and the heavy journey we were sharing - eyes down, hands twisting - we took our time with sadness. As their breaths slowed, our gazes would meet again to reconnect. Unsure of this intimacy and how to proceed, they would say: "I'm sorry for crying." With no words to stop the pain, no honest promises to keep, my hand would alight on a thin arm or a shaking knee and I would simply say: "There are no apologies needed for grief."

But there is no easy way to bridge the physical distance of a telephone call. How is she sitting? Where is she looking? Is there a warm blanket drawn to her chin or a cat nearby for comfort?
Has she been crying all along, contained and silent until a gasp went unchecked?

Wait, I tell myself. Just wait. In that space, in that defining moment, my chest starts to feel the familiar pull the essence of pain from the other end of the telephone line - flowing through to me like an intravenous drip making its way into a patient's body. I wait. I wait until her breath slows. I wait until I am certain it is time to speak. I wait until she is ready to move forward and only then do I speak. And if she says she is sorry, I will simply say: "There are no apologies needed for grief."

\section{Eve Makoff MD}

MedZed

Los Angeles, Calif.

This article has been peer reviewed.

All characters in this work are fictitious. Any resemblance to real persons, living or dead, is purely coincidental.

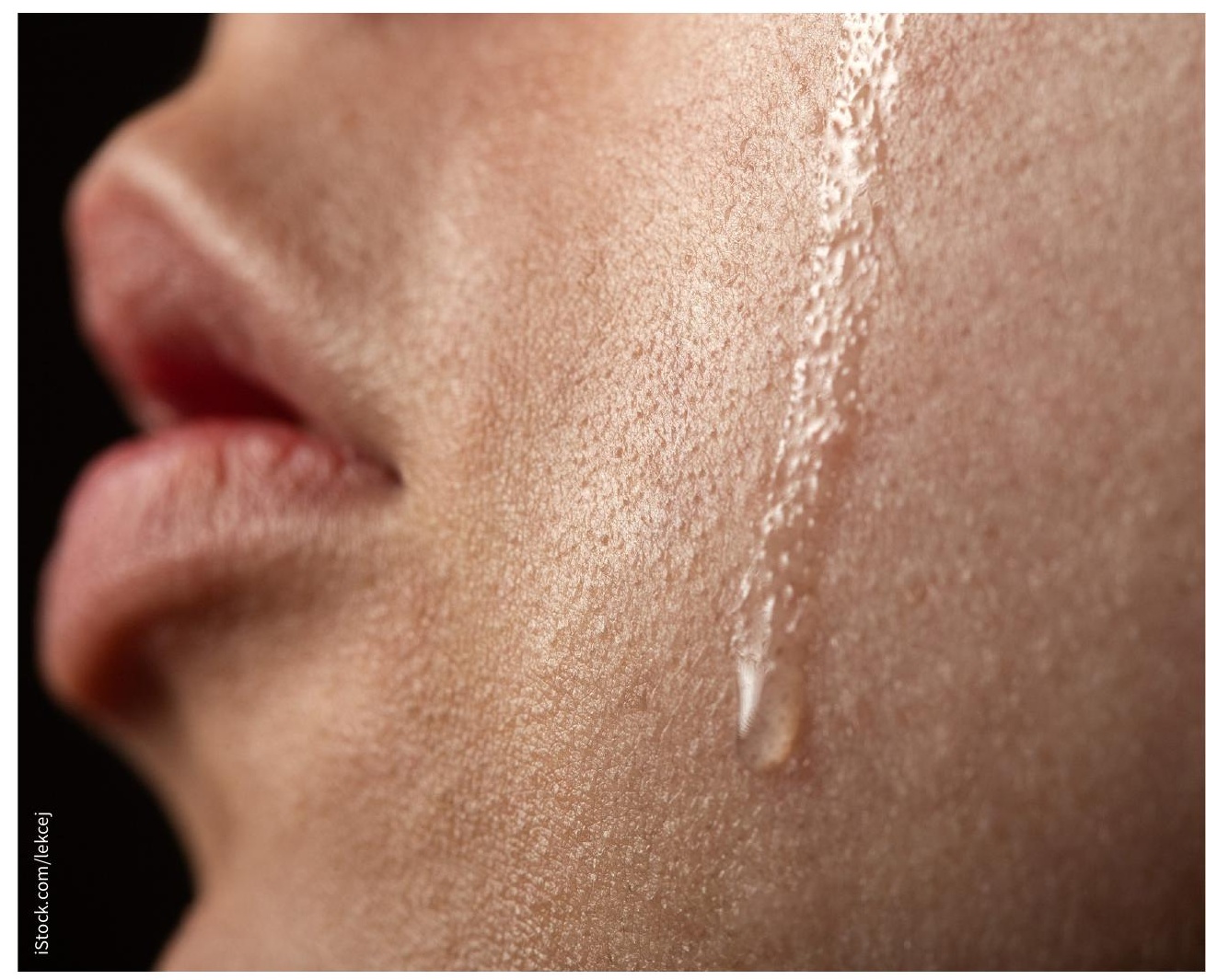

